\title{
Kinetics of the solvent-free hydrogenation of 2-methyl-3-butyn-2-ol over a structured Pd-based catalyst
}

\author{
Micaela Crespo-Quesada, Martin Grasemann, Natalia Semagina, Albert Renken, Lioubov Kiwi-Minsker* \\ Group of Catalytic Reaction Engineering, Ecole Polytechnique Fédérale de Lausanne, EPFL-SB-ISIC-GGRC, Station 6, CH-1015 Lausanne, Switzerland
}

\section{A R T I C L E I N F O}

\section{Article history:}

Available online 28 November 2008

Dedicated to the 60th birthday of Prof. Marc Ledoux.

\section{Keywords:}

Hydrogenation

Kinetics modeling

Palladium

Structured catalyst

Design of experiments

2-Methyl-3-butyn-2-ol

\section{Introduction}

The selective catalytic hydrogenation of alkynols to alkenols is an important process in the fine chemicals industry [1,2]. Pd-based catalysts are known to give the highest selectivity and yield [3]. Their performance is strongly influenced by the dispersion of the active metal [4,5], the nature of the support [6,7] and the use of promoters [8] and additives [9].

In industry, these reactions are mostly carried out in slurry reactors with Lindlar catalyst [10]. In such cases, the influence of mass transfer may decrease the catalyst performance [11] and thus must be taken into consideration. Furthermore, the Lindlar catalyst used as a fine powder is difficult to handle requiring filtration after the reaction.

\footnotetext{
* Corresponding author.

E-mail address: lioubov.kiwi-minsker@epfl.ch (L. Kiwi-Minsker). Abbreviations: AAS, atomic absorption spectroscopy; ANOVA, analysis of the variance; BE, binding energy; BPC, Büchi pressflow controller; CCD, central composite design; D, dimers; DF, degrees of freedom (ANOVA); DOE, design of experiments; F, F-ratio (ANOVA); MBA, 2-methyl-3-butan-2-ol; MBE, 2-methyl-3buten-2-ol; MBY, 2-methyl-3-butyn-2-ol; MS, mean square (ANOVA); OFAT, onefactor-at-a-time; $P$, probability of being noise (ANOVA); SBCR, staged bubble column reactor; SMF, sintered metal filters; SS, sum of squares (ANOVA); XPS, X-ray photoelectron spectroscopy; XRD, X-ray diffraction.
}

To overcome these problems, a continuous staged bubble column reactor (SBCR) has been suggested [12]. It presents improved mass transfer between the liquid and the gas phase while hindering backmixing [13,14]. The operation of SBCR requires an effective structured catalyst to be used as catalytic stages.

Recently, a structured Pd-based catalyst supported on sintered metal fibers (SMF) has been developed in our group [15]. The SMF are coated with a $\mathrm{ZnO}$ layer on which pre-synthesized Pd nanoparticles are deposited. The catalyst showed an excellent performance in the water-assisted selective hydrogenation of 2methyl-3-butyn-2-ol (MBY) to 2-methyl-3-buten-2-ol (MBE) with a complete hindrance of the over-hydrogenation reaction to 2methyl-3-butan-2-ol (MBA). This high selectivity towards MBE was due to the formation of an inter-metallic phase (PdZn) obtained after subjecting the catalyst to a high-temperature treatment under hydrogen [15]. Furthermore, the SMF panels coated with $\mathrm{ZnO}$ presented an open structure and, thus, were found to have a low-pressure drop in an SBCR [13].

In this work, the kinetic behaviour of a $\mathrm{Pd} / \mathrm{ZnO} / \mathrm{SMF}$ structured catalyst in the solvent-free selective hydrogenation of MBY to MBE was studied in order to evaluate its feasibility for the application in an SBCR. MBE is an intermediate in the synthesis of vitamins A and $\mathrm{E}$ and perfumes (Fig. 1). The catalyst was characterized by atomic absorption spectroscopy (AAS), X-ray diffraction (XRD) and X-ray 


\section{Nomenclature}

$a_{0} \quad$ constant effect of the CCD design

$a_{i} \quad$ main half effects of the CCD design

$a_{i i} \quad$ second-order half effects of the CCD design

$a_{i j} \quad$ first-order interaction half effects of the CCD design

A apparent pre-exponential factor $\left(\mathrm{m}^{3} \mathrm{~mol}_{\mathrm{Pd}}^{-1} \mathrm{~s}^{-1}\right)$

$\mathrm{C}_{\mathrm{H}_{2}} \quad$ hydrogen bulk concentration $\left(\mathrm{mol} \mathrm{m}^{-3}\right)$

$C_{i} \quad$ concentration of $i\left(\mathrm{~mol} \mathrm{~L}^{-1}\right)$

$E_{\mathrm{a}} \quad$ apparent activation energy $\left(\mathrm{kJ} \mathrm{mol}^{-1}\right)$

$k_{i}^{\prime} \quad$ apparent kinetic constant of the reaction $i$ $\left(\mathrm{L} \mathrm{mol}_{\mathrm{Pd}}^{-1} \mathrm{~s}^{-1}\right)$

$K_{i} \quad$ adsorption constant of $i\left(\mathrm{~L} \mathrm{~mol}^{-1}\right)$

$K_{i}^{*} \quad$ adsorption constant of the intermediate $i$

$M_{i} \quad$ molecular weight of $i\left(\mathrm{~g} \mathrm{~mol}^{-1}\right)$

$n_{\mathrm{Pd}} \quad$ amount of active material in the catalyst (mol)

$r_{i} \quad$ rate of the reaction $i\left(\mathrm{~mol} \mathrm{~mol}_{\mathrm{Pd}}^{-1} \mathrm{~s}^{-1}\right)$

$r_{i}^{0} \quad$ initial reaction rate $\left(\mathrm{mol} \mathrm{mol}_{\mathrm{Pd}}^{-1} \mathrm{~s}^{-1}\right)$

$S \quad$ selectivity towards $\operatorname{MBE}(\%)$

$u_{i} \quad$ standardized variable of the CCD design

$V_{\mathrm{L}} \quad$ volume of liquid in the reaction (L)

$w_{i} \quad$ mass fraction (\%)

$x_{i} \quad$ molar fraction (\%)

$X \quad$ conversion of MBY (\%)

\section{Greek letter}

$\rho_{0} \quad$ density of the reaction mixture $\left(\mathrm{g} \mathrm{L}^{-1}\right)$

photoelectron spectroscopy (XPS). Its performance was compared to that of the industrial Lindlar catalyst. The catalyst reuse and the influence of a sulphur-containing additive were also studied. The reaction kinetics was modelled based on a Langmuir-Hinshelwood mechanism considering competitive adsorption for the organic species and dissociative adsorption of hydrogen [16]. The planning and analysis of the kinetic experiments was done through a design of experiments (DOE) methodology. In this kind of approach, the parameters that affect a given response are varied simultaneously. Classically, the estimation of the apparent coefficients is done by performing one-factor-at-a-time (OFAT) experiments, which vary only one parameter while keeping the others fixed. However, statistically designed experiments, or DOE, vary several factors simultaneously [17]. In general, DOE presents many advantages as compared to OFAT approaches being less time consuming for the same amount of information obtained.
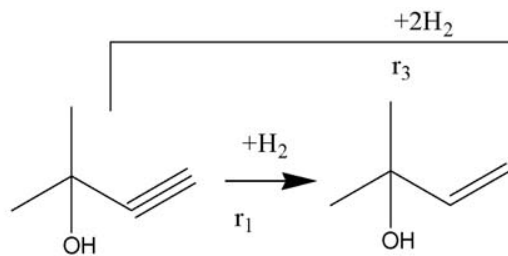

2-methyl-3-butyn-2-ol (MBY)

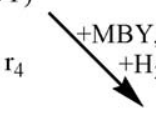

2-methyl-3-buten-2-ol (MBE)

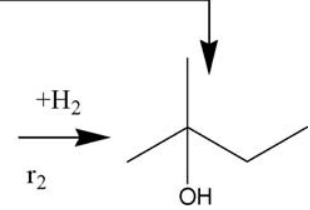

2-methylbutan-2-ol (MBA)
Moreover, the values of the model parameters are more accurate and the interaction between factors can be estimated systematically. DOE also provides information for a larger experimental region using the same amount of experimental data [17]. The most important feature of DOE is that the results obtained are backed by a solid statistical background [18]. The application of DOE to obtain kinetic data is not recent although it has not been hitherto widely used [19-21].

\section{Experimental}

\subsection{Materials}

SMF made of FeCrAl alloy fibers ( $\mathrm{Cr} 20 \%, \mathrm{Al} 4.75 \%$, Y 0.27\%, other elements $\sim 1-2 \%$, Fe balance) in the form of a uniform porous panel ( $0.29 \mathrm{~mm}$ thickness, $71 \%$ porosity, $20 \mu \mathrm{m}$ fiber thickness, $675 \mathrm{~g} /$ $\mathrm{m}^{2}$ ) [22] were used as a structured support.

2-Methyl-3-butyn-2-ol (purum, $\geq 99 \%$ ), 2-methyl-3-buten-2-ol (purum, $\geq 97 \%$ ), 2-methyl-2-butanol (purum, $\geq 98 \%$ ) and $\mathrm{ZnO}$ powder were purchased from Fluka and used as received. Hydrogen ( $\geq 99.99 \%$ purity) was acquired from Carbagas, Switzerland. Bidistilled water was used throughout this work.

\subsection{Catalyst preparation}

The preparation of the structured $\mathrm{Pd} / \mathrm{ZnO} / \mathrm{SMF}$ catalyst used throughout this work was described in detail elsewhere [15]. Briefly, the SMF panels were degreased, calcined and covered with a thin film of $\mathrm{ZnO}$ via a sol-gel method, which was found to be inert in the studied reaction. Pd nanoparticles prepared beforehand via electrostatical stabilization were deposited on $\mathrm{ZnO} / \mathrm{SMF}$ material. The only difference in the procedure consists in the suppression of the last reduction step at high temperature. As a consequence, there was no deliberate formation of the intermetallic PdZn phase.

The powdered $5 \mathrm{wt}$ \% $\mathrm{Pd} / \mathrm{ZnO}$ catalyst was prepared by wet impregnation using the same Pd-nanoparticle solution of an adequate concentration. The $\mathrm{ZnO}$ powder was previously calcined to eliminate all residues at $693 \mathrm{~K}$ for $3 \mathrm{~h}$.

\subsection{Catalyst characterization}

To determine the amount of Pd, the catalyst was dissolved in hot nitric acid and the sample was analyzed by atomic absorption spectroscopy (AAS) via a Shimadzu AA-6650 spectrometer with an air-acetylene flame.

An ultrasonic adherence test for the mechanical stability of the catalyst was carried out using an ultrasonic bath (Bransonic ultrasonic cleaner, Branson Ultrasonic Corp., USA). The catalyst was immersed in isopropanol and sonicated for $10 \mathrm{~min}$.

XRD analyses were carried out in a Siemens D 500 diffractometer using $\mathrm{Cu} \mathrm{K} \alpha$ radiation. The spectra of the $5 \% \mathrm{Pd} / \mathrm{ZnO}$ powder samples were recorded in a rapid scanning mode $(4.0 \mathrm{~s} /$ step, $2 \theta$ step size of $0.04^{\circ}$ ) in a $2 \theta$ range of $30-50^{\circ}$. For the calculation of the particle size of Pd, Scherrer's equation was used.

XPS of the powder $5 \% \mathrm{Pd} / \mathrm{ZnO}$ samples was performed using an Axis Ultra ESCA system (Kratos, Manchester) with monochromated $\mathrm{Al} \mathrm{K} \alpha$ radiation $(1486.6 \mathrm{eV}$ ) and an X-ray power of $150 \mathrm{~W}$. The binding energy (BE) values were referenced against a $C$ $1 \mathrm{~s}=285.0 \mathrm{eV}$ line.

\subsection{Hydrogenation experiments}

The reactions were carried out in a semi-batch stainless steel reactor ( $250 \mathrm{~mL}$ autoclave, Büchi AG, Uster, Switzerland) equipped

Fig. 1. Reaction scheme for the hydrogenation of MBY 
with a heating jacket and a hydrogen supply system. The structured Pd/ZnO/SMF catalyst was placed between two metal gauzes $(2 \mathrm{~cm} \times 8.5 \mathrm{~cm})$ fixed on a self-gassing hollow shaft which was used as stirrer. For the reactions in which either the Lindlar or the powder catalysts were tested, an 8-blade disk turbine impeller was used as stirrer. In some experiments, a sulphur-containing modifier was added to the reaction medium.

After the reactor was charged, it was flushed with $\mathrm{N}_{2}$ and set to the target temperature. Then the reactor was flushed with $\mathrm{H}_{2}$ and pressurized. The consumption of hydrogen was monitored using a pressflow gas controller (BPC-6002) (Büchi, Switzerland).

Samples were periodically withdrawn from the reactor and analyzed by GC. The GC analysis was performed using an Auto System XL (PerkinElmer) equipped with a $30 \mathrm{~m}$ Stabilwax (Crossbond Carbowax-PEG, Restek, USA) $0.32 \mathrm{~mm}$ capillary column with a $0.25 \mu$ coating. The carrier gas (He) pressure was $101 \mathrm{kPa}$. The temperature of the Injector and the FID were $473 \mathrm{~K}$ and $523 \mathrm{~K}$, respectively. The oven temperature was held for $4 \mathrm{~min}$ at $323 \mathrm{~K}$, then increased to $473 \mathrm{~K}$ at a rate of $30^{\circ} / \mathrm{min}$. The accuracy of the analysis was found to be of $0.1 \%$ for all products except for the dimmers (3\%). The GC analysis allowed detecting also the dimerized by-products formed during the reaction. The average molar weight of the dimers was assumed to be $160 \mathrm{~g} \mathrm{~mol}^{-1}$.

The molar fraction percentages were calculated from mass fraction percentages (given by GC analysis):

$x_{i}=\frac{w_{i} / M_{i}}{\sum w_{i} / M_{i}} \times 100$

The conversion, selectivity and yield were defined as

$X=100-x_{\mathrm{MBY}}$

$S=\frac{x_{i}}{\sum_{\text {products }} x_{i}} \times 100$

$Y=\frac{X \cdot S_{i}}{100}$

The molar concentration of each species was calculated assuming that the density of the reacting mixture remained constant and equal to that of $\operatorname{MBY}\left(0.86 \mathrm{~g} \mathrm{~mL}^{-1}\right)$ and was defined as

$C_{i}=\frac{w_{i} / 100 \cdot \rho_{0}}{M_{i}}$

The initial activities were considered as the rate of hydrogen consumption between 4 and 6\% MBY conversion.

In the kinetic experiments, the concentration of hydrogen in the liquid phase was monitored online with a hydrogen analyzer Fugatron HYD-100 (DMP, Switzerland) as described elsewhere [23]. The permeation probe operated with a carrier gas flow of $30 \mathrm{~cm}^{3}$ (STP) $\mathrm{min}^{-1}$. The active area of the probe was $8 \mathrm{~cm}^{2}$. The concentration of hydrogen was thus kept constant by adjusting the pressure of the reactor vessel when necessary. This device has been recently used in our group for the estimation of the gas-liquid mass transfer coefficient in the hydrogenation of MBY to MBE with a Lindlar catalyst [11].

\subsection{Catalyst reuse}

The $\mathrm{Pd} / \mathrm{ZnO} / \mathrm{SMF}$ catalyst was reused in multiple runs. After each run, the catalyst was washed twice in isopropanol (to dissolve possible deposits), dried under vacuum conditions overnight at $323 \mathrm{~K}$ and stored in a vacuum-dessicator for not more than 2 days before the next run.

\section{Results and discussion}

\subsection{Catalyst performance}

A typical experiment (Fig. 2) shows the concentration of MBE going through a maximum when the conversion of $\mathrm{MBY}$ is around $100 \%$ and then decreasing again as a result of the further hydrogenation to MBA. On the other hand, the formation of dimers stops when all MBY has been consumed. The rate of the semi-hydrogenation of MBY to MBE was found to be an order of magnitude higher than that found for the catalyst in water-assisted conditions. Nevertheless, the over-hydrogenation rate of MBE to MBA was much slower than that reported for Pd and PdPb catalysts [24], but yet not zero, as was the case in the water-assisted reaction [15]. These two findings could be attributed to the presence of the $\mathrm{PdZn}$ phase in the latter since $\mathrm{Pd} / \mathrm{Al}_{2} \mathrm{O}_{3}$ and $\mathrm{Pd} / \mathrm{ZnO}$ powdered catalysts were previously compared in our group showing the presence of the PdZn phase in the latter even when no hightemperature treatment had been applied. Neither of the catalysts fully hindered the over-hydrogenation of MBE, although this reaction was slower in the case of $\mathrm{Pd} / \mathrm{ZnO}$ [15].

When the reactions were carried out without any additives, the selectivity towards MBE was found to be between 97 and $98 \%$ and remained constant up to $99 \%$ conversion of MBY. The maximum yield of around $96 \%$ was achieved at an MBY conversion of approximately $99 \%$.

\subsection{Influence of additives}

It is known that the use of additives (or modifiers) may increase the selectivity and/or block the consecutive over-hydrogenation reaction due to a preferential adsorption of the additives over olefins [25]. The use of additives is often applied in industry to prevent a decrease in selectivity, due to an imprecisely defined reaction time, by blocking the over-hydrogenation reaction.

Typical kinetic curves showed that the consumption of MBE was strongly reduced at MBY conversion $>95 \%$ when a sulphurcontaining modifier was present in the reaction mixture. However, the selectivity was found to be around $98 \%$ and a maximum yield of over $97 \%$ was reached at nearly total MBY conversion. Three different modifier concentrations were tested. The time to full conversion increased by $37 \%$ regardless the amount of modifier, which suggests that some active sites become blocked even for the adsorption of MBY. At a molar ratio of modifier to Pd of 7 the rate of

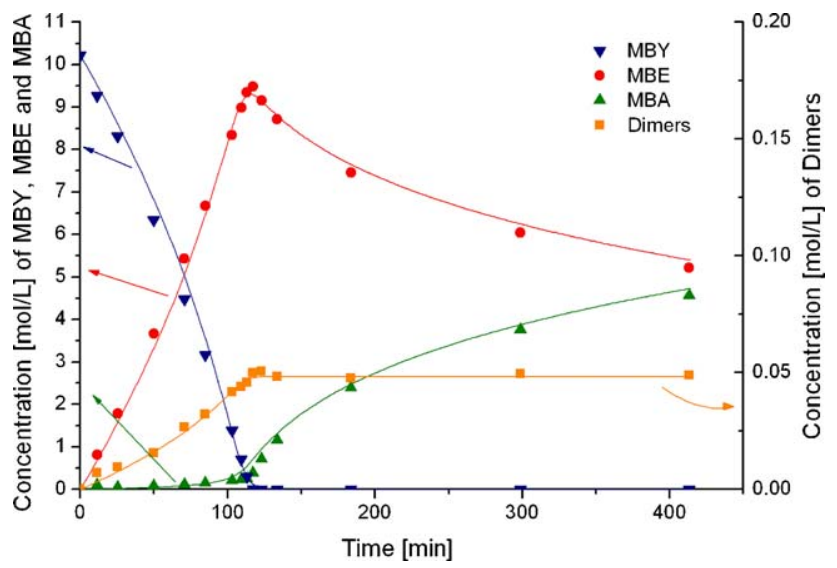

Fig. 2. Experimental points and kinetic curves modelled with Berkeley Madonna Software. Conditions: $200 \mathrm{~g}$ of MBY, $348 \mathrm{~K}, 19.2 \mathrm{~mol} / \mathrm{m}^{3}$ of $\mathrm{H}_{2}$ (approximately $0.8 \mathrm{MPa}), 0.3829 \mathrm{~g}$ of $0.2 \% \mathrm{Pd} / \mathrm{ZnO} / \mathrm{SMF}$ catalyst. 
over-hydrogenation decreased by $78 \%$. When the ratio was one, the rate decreased by only $30 \%$.

\subsection{Catalyst reuse}

The Pd/ZnO/SMF catalyst was subjected to 10 consecutive runs under the same conditions. The catalyst was cleaned between each run with isopropanol in ultrasound for $10 \mathrm{~min}$ as this procedure was shown to regenerate the catalyst after the water-assisted hydrogenation of MBY [15]. During the consecutive runs the catalyst showed deactivation and an increase in selectivity (Fig. 3). The selectivity at $95 \%$ conversion slightly increased $(\sim 0.5 \%$ from runs 1 to 10). On the other hand, whereas the overall loss of activity over 10 runs was $38 \%$ (from 18 to $11\left[\mathrm{~mol} \mathrm{~mol}_{\mathrm{Pd}}^{-1} \mathrm{~s}^{-1}\right]$ ), the loss of active Pd due to leaching was only $\sim 15 \%$. This suggests that the catalyst underwent some changes that led to its deactivation. Further experiments showed that most of the Pd probably leached out during the first run being in agreement with the higher activity loss between the 1 st and 2 nd run (17\%).

The performance of the $\mathrm{Pd} / \mathrm{ZnO} / \mathrm{SMF}$ structured catalyst after the 10th run was compared to the performance of an industrial Lindlar catalyst. The time to full conversion for the Lindlar catalyst was $\sim 50 \%$ higher than that of the structured catalyst whereas the yield and the selectivity were the same for both.

\subsection{Catalyst characterization}

In order to explain the loss of activity and the increase of selectivity during the catalyst reuse, XRD and XPS analyses were carried out. The measurements were not performed directly over the $\mathrm{Pd} / \mathrm{ZnO} / \mathrm{SMF}$ structured catalysts because of technical problems related to the geometry of the sample and the overshadowing effect of the components of the SMF. Instead, they were performed over a powder $5 \% \mathrm{Pd} / \mathrm{ZnO}$ fresh and used catalyst (after two runs).

Fig. 4 shows the XPS spectra of the fresh and used $\mathrm{Pd} / \mathrm{ZnO}$ catalyst which revealed the same results as when the catalyst reduction in hydrogen had been performed, except for the number of Pd species found. Three species were found in the studied catalyst: $\mathrm{Pd}^{2+}$ corresponding to $\mathrm{PdO}$ (BE of $337.0 \mathrm{eV}$ in the $3 \mathrm{~d}_{5 / 2}$ spectrum), $\mathrm{Pd}(0)$ corresponding to metallic $\mathrm{Pd}$ (BE of $335.0 \mathrm{eV}$ in the $3 d_{5 / 2}$ spectrum) and $\operatorname{Pd}(0)$ from the $P d Z n$ phase (BE of $335.6 \mathrm{eV}$ in the $3 d_{5 / 2}$ spectrum [26]). The distribution of the different types

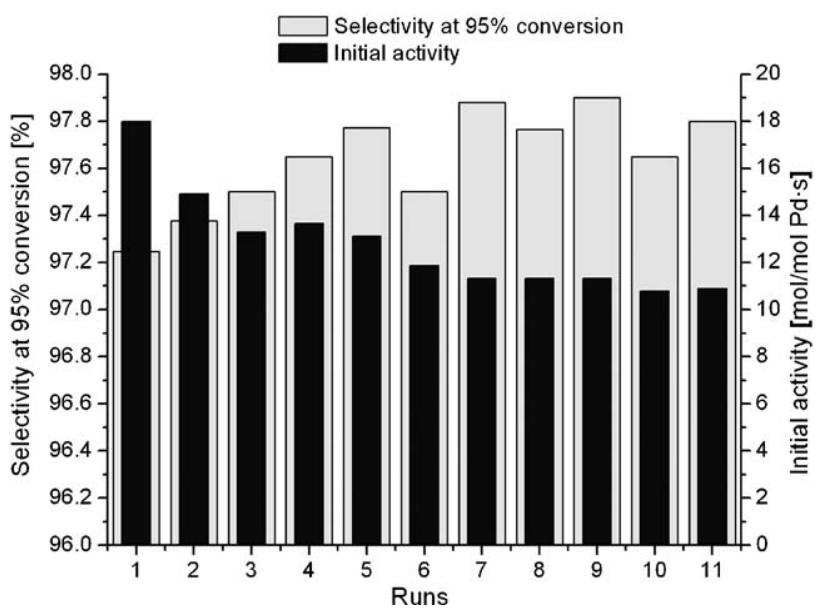

Fig. 3. Effect of catalyst reuse on the initial activity and selectivity in the selective hydrogenation of MBY. Run number 11 corresponds to the catalyst after the ultrasonic treatment. Conditions: $172 \mathrm{~g}$ of MBY, $343 \mathrm{~K}, 0.5 \mathrm{MPa}$ of $\mathrm{H}_{2}, 1.1600 \mathrm{~g}$ of $0.17 \% \mathrm{Pd} / \mathrm{ZnO} / \mathrm{SMF}$ catalyst, $0.0247 \mathrm{~g}$ of modifier.
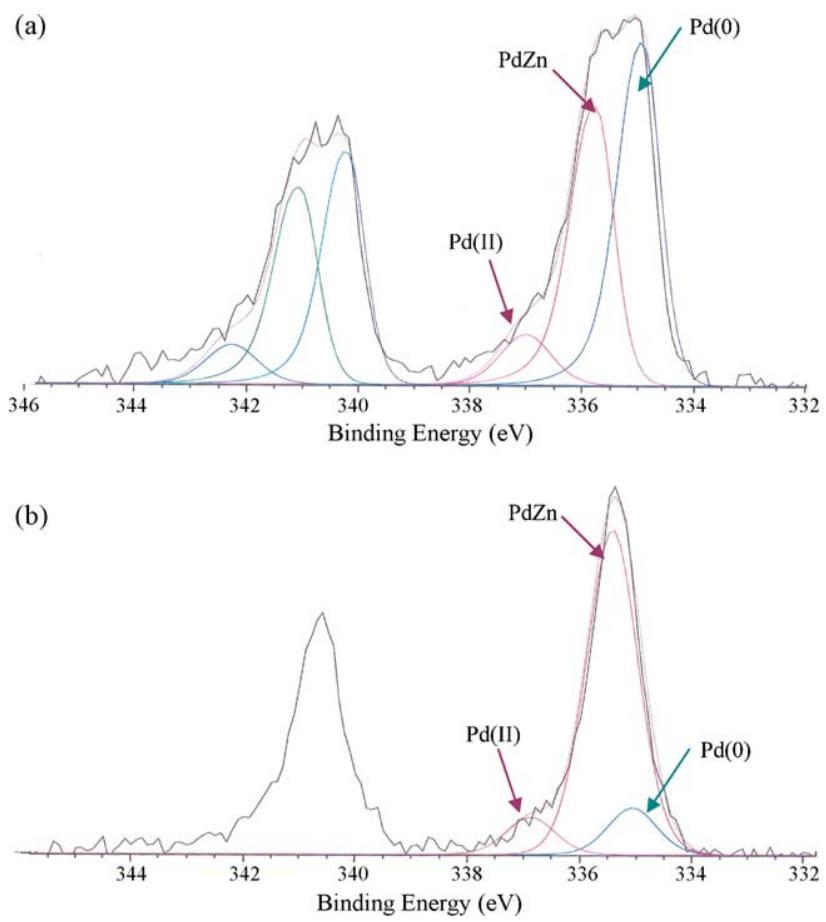

Fig. 4. XPS spectra of the powder $5 \% \mathrm{Pd} / \mathrm{ZnO}$ catalyst (a) fresh and (b) after two runs Conditions 1 st run: $172 \mathrm{~g}$ of $\mathrm{MBY}, 338 \mathrm{~K}, 0.5 \mathrm{MPa}$ of $\mathrm{H}_{2}, 0.7016 \mathrm{~g}$ of catalyst, $0.0404 \mathrm{~g}$ of modifier. Conditions 2nd run: $172 \mathrm{~g}$ of MBY, $338 \mathrm{~K}, 0.5 \mathrm{MPa}$ of $\mathrm{H}_{2}$, $0.6035 \mathrm{~g}$ of catalyst, $0.0347 \mathrm{~g}$ of modifier.

of palladium of the fresh catalyst was 49 at.\% of $\mathrm{Pd}(0), 9$ at.\% of $\mathrm{Pd}^{2+}$ and 42 at.\% of $\operatorname{Pd}(0)$ from the PdZn phase. In spite of not having subjected the catalyst to a high temperature treatment under hydrogen, the PdZn phase was formed being in line with the known interaction between Pd and $\mathrm{ZnO}$ even under storage in air [27]. This interaction is enhanced in the reducing atmosphere of the hydrogenation reactions. Indeed, after two runs the amount of $\operatorname{Pd}(0)$ dropped to 11 at.\%, while the amount of $\operatorname{Pd}(0)$ involved in the PdZn phase increased to 80 at.\%. It is interesting to note that the reduction does not eliminate $\mathrm{PdO}$ from the catalyst surface.

Both the fresh and used samples were analyzed by XRD and the presence of a PdZn phase was confirmed [15]. The average size of the fresh Pd crystallites was calculated using Scherrer's equation and was found to be approximately $7 \mathrm{~nm}$. A slight increase in their size was found in the used catalyst $(0.8 \mathrm{~nm})$.

Usual causes for deactivation in liquid-phase reactions are the irreversible adsorption of chemical species or poisons (such as Scompounds) or the deactivation by oligomeric species or byproducts [28]. It's been shown that coke formation is less abundant in liquid-phase reactions compared to gas-phase hydrogenations [29]. The XPS analyses carried out on powdered Pd/ZnO suggest the accumulation of $C$ on the surface of the catalyst (2\% after two runs) probably due to the oligomeric by-products since the accumulation of the additive was ruled out given that no sulphur was observed in the measurements.

Thus, the formation of the inter-metallic PdZn phase is believed to be the main responsible for the improvement of the catalyst's selectivity and loss of activity during reuse. Zinc acts as a promoter $[8,30]$ and is known to increase the selectivity and reduce the activity of Pd in the hydrogenation of MBY [7,31] due to a weaker adsorption of both MBY and hydrogen, and a hindrance of the adsorption of MBE [7].

No changes in either activity or selectivity were detected after the ultrasonic treatment, indicating that this procedure did not regenerate the catalyst. 


\subsection{Intrinsic kinetics studied with DOE}

\subsubsection{Langmuir-Hinshelwood mechanism}

For the development of the Langmuir-Hinshelwood kinetic expressions, one type of active site was assumed as well as dissociative adsorption of hydrogen [32] and bimolecular reactions between the adsorbed species.

The reaction network is shown below (see also Fig. 1):

$$
\begin{aligned}
& \mathrm{MBY}+\mathrm{H}_{2} \stackrel{k_{1}}{\longrightarrow} \mathrm{MBE}+\mathrm{H}_{2} \stackrel{k_{2}}{\longrightarrow} \mathrm{MBA} \\
& \mathrm{MBY}+2 \mathrm{H}_{2} \stackrel{k_{3}}{\longrightarrow} \mathrm{MBA} \\
& 2 \mathrm{MBY}+2 \mathrm{H}_{2} \stackrel{k_{4}}{\longrightarrow} \mathrm{D}
\end{aligned}
$$

Table 1 shows the elementary steps of each reaction together with their kinetic expression. The rate determining steps were chosen based on the fact that hydrogenations usually involve dissociative adsorption of hydrogen over Pt group metals and present a firstorder toward hydrogen [16]. This implied a two-step hydrogenation of each species leading to an intermediate compound.

The application of the Langmuir-Hinshelwood mechanism led to the expressions shown in Table 2 . It is worth mentioning that the mass balance for the surface coverage was performed assuming a low-coverage for all intermediate species:

$1=\theta_{\sigma}+\theta_{\mathrm{MBY}}+\theta_{\mathrm{MBE}}+\theta_{\mathrm{MBA}}+\theta_{\mathrm{D}}+\theta_{\mathrm{H}}$

And thus, the coverage of active sites becomes:

$\theta_{\sigma}=\frac{1}{K_{\mathrm{MBY}} C_{\mathrm{MBY}}+K_{\mathrm{MBE}} C_{\mathrm{MBE}}+K_{\mathrm{MBA}} C_{\mathrm{MBA}}+K_{\mathrm{D}} C_{\mathrm{D}}+K_{\mathrm{H}_{2}} C_{\mathrm{H}_{2}}}$

It can be seen that the constants of the intermediate components $K_{i}^{n *}$, where the number of asterisks represent the number of atoms of hydrogen attached to the molecule, are dimensionless. Grouping all constant terms of the numerator and assuming that $K_{\mathrm{MBA}}=K_{\mathrm{D}}=K$, provided that the adsorption constant of the products is smaller than that of MBY, led to the simplified expressions shown in Table 3.

\begin{tabular}{|c|c|c|c|}
\hline Reaction & Step & Chemical reaction & Kinetic expression \\
\hline \multirow[t]{5}{*}{$\mathrm{MBY} \rightarrow \mathrm{MBE}$} & 1 & $\mathrm{MBY}+\sigma \stackrel{K_{\mathrm{MBY}}}{\longrightarrow} \mathrm{MBY} \sigma$ & $K_{\mathrm{MBY}}=\frac{\theta_{\mathrm{MBY}}}{C_{\mathrm{MBY}} \cdot \theta_{\sigma}}$ \\
\hline & 2 & $\mathrm{H}_{2}+2 \sigma \stackrel{\mathrm{K}_{\mathrm{H}_{2}}}{\longleftrightarrow} 2\left(\mathrm{H}_{\sigma}\right)$ & $K_{\mathrm{H}_{2}}=\frac{\theta_{\mathrm{H}}^{2}}{C_{\mathrm{H}_{2}} \cdot \theta_{\sigma}^{2}}$ \\
\hline & 3 & $\mathrm{MBY} \sigma+\mathrm{H} \sigma \stackrel{K_{\mathrm{MBY}}^{*}}{\longrightarrow} \mathrm{MBY}^{*} \sigma+\sigma$ & $K_{\mathrm{MBY}}^{*}=\frac{\theta_{\mathrm{MBB}^{*}} \cdot \theta_{\sigma}}{\theta_{\mathrm{MBY}} \cdot \theta_{\mathrm{H}}}$ \\
\hline & $4^{\mathrm{a}}$ & $\mathrm{MBY}^{*} \sigma+\mathrm{H} \sigma \stackrel{k_{1}}{\longrightarrow} \mathrm{MBE} \sigma+\sigma$ & $r_{1}=k_{1} \cdot \theta_{\mathrm{MBY}^{*}} \cdot \theta_{\mathrm{H}}$ \\
\hline & 5 & $\mathrm{MBE} \sigma \stackrel{K_{\mathrm{MBE}}}{\longrightarrow} \mathrm{MBE}+\sigma$ & $K_{\mathrm{MBE}}=\frac{\theta_{\mathrm{MBE}}}{C_{\mathrm{MBE}} \cdot \theta_{\sigma}}$ \\
\hline \multirow[t]{3}{*}{$\mathrm{MBE} \rightarrow \mathrm{MBA}$} & 1 & $\mathrm{MBE} \sigma+\mathrm{H} \sigma \stackrel{K_{\mathrm{MBE}}^{*}}{\longrightarrow} \mathrm{MBE}^{*} \sigma+\sigma$ & $K_{\mathrm{MBE}}^{*}=\frac{\theta_{\mathrm{MBE}^{*}} \cdot \theta_{\sigma}}{\theta_{\mathrm{MBE}} \cdot \theta_{\mathrm{H}}}$ \\
\hline & $2^{\mathrm{a}}$ & $\mathrm{MBE}^{*} \sigma+\mathrm{H} \sigma \stackrel{k_{2}}{\longrightarrow} \mathrm{MBA} \sigma+\sigma$ & $r_{2}=k_{2} \cdot \theta_{\mathrm{MBE}^{*}} \cdot \theta_{\mathrm{H}}$ \\
\hline & 3 & $\mathrm{MBA} \sigma \stackrel{K_{\mathrm{MBA}}}{\longrightarrow} \mathrm{MBA}+\sigma$ & $K_{\mathrm{MBA}}=\frac{\theta_{\mathrm{MBA}}}{C_{\mathrm{MBA}} \cdot \theta_{\sigma}}$ \\
\hline \multirow[t]{3}{*}{$\mathrm{MBY} \rightarrow \mathrm{MBA}$} & 1 & $\mathrm{MBY}^{*} \sigma+\mathrm{H} \sigma \stackrel{K_{\mathrm{MBY}}^{* *}}{\longrightarrow} \mathrm{MBY}^{* *} \sigma+\sigma$ & $K_{\mathrm{MBY}}^{* *}=\frac{\theta_{\mathrm{MBY}^{*} \cdot \theta_{\sigma}}}{\theta_{\mathrm{MBY}^{*} \cdot \theta_{\mathrm{H}}}}$ \\
\hline & 2 & $\mathrm{MBY}^{* *} \sigma+\mathrm{H} \sigma \stackrel{{ }_{\mathrm{MBY}}{ }^{* * *}}{\longrightarrow} \mathrm{MBY}^{* * *} \sigma+\sigma$ & $K_{\mathrm{MBY}}^{* * *}=\frac{\theta_{\mathrm{MBY}^{* * *} \cdot \theta_{\sigma}} \theta_{\mathrm{MBY}^{* *}} \cdot \theta_{\mathrm{H}}}{2}$ \\
\hline & $3^{\mathrm{a}}$ & $\mathrm{MBY}^{* * *} \sigma+\mathrm{H} \sigma \stackrel{k_{3}}{\longrightarrow} \mathrm{MBA} \sigma+\sigma$ & $r_{3}=k_{3} \cdot \theta_{\mathrm{MBY}^{* * *}} \cdot \theta_{\mathrm{H}}$ \\
\hline \multirow[t]{3}{*}{$\mathrm{MBY} \rightarrow \mathrm{D}$} & $1^{\mathrm{a}}$ & $\mathrm{MBY}^{*} \sigma+\mathrm{H} \sigma \stackrel{k_{4}}{\longrightarrow} \mathrm{MBY}^{* *} \sigma+\sigma$ & $r_{4}=k_{4} \cdot \theta_{\mathrm{MBY}^{*}} \cdot \theta_{\mathrm{H}}$ \\
\hline & 2 & $\mathrm{MBY}^{* *} \sigma+\mathrm{MBY}^{* *} \sigma \stackrel{K_{\mathrm{MBY}}^{* * *}}{\longrightarrow} \mathrm{D} \sigma+\sigma$ & $K_{\mathrm{MBY}}^{* * * *}=\frac{\theta_{\mathrm{D}} \cdot \theta_{\sigma}}{\theta_{\mathrm{MBY}^{* *}}^{2}}$ \\
\hline & 3 & $\mathrm{D} \sigma \stackrel{K_{D}}{\longrightarrow} \mathrm{D}+\sigma$ & $K_{\mathrm{D}}=\frac{\theta_{\mathrm{D}}}{C_{\mathrm{D}} \cdot \theta_{\sigma}}$ \\
\hline
\end{tabular}

Table 1

Langmuir-Hinshelwood mechanism for the hydrogenation of MBY.

${ }^{a}$ Rate determining step (RDS).

The mass balances for MBY and the reaction products are given by the following differential equations:

$$
\begin{aligned}
& \frac{\mathrm{d} C_{\mathrm{MBY}}}{\mathrm{d} t}=\frac{n_{\mathrm{Pd}}}{V_{\mathrm{L}}}\left(-r_{1}-r_{3}-2 r_{4}\right) \\
& \frac{\mathrm{d} C_{\mathrm{MBE}}}{\mathrm{d} t}=\frac{n_{\mathrm{Pd}}}{V_{\mathrm{L}}}\left(r_{1}-r_{2}\right)
\end{aligned}
$$

\begin{tabular}{|c|c|c|}
\hline Reaction & Langmuir-Hinshelwood expression & \\
\hline $\mathrm{MBY} \rightarrow \mathrm{MBE}$ & $r_{1}=\frac{k_{1} \cdot K_{\mathrm{MBY}}^{*} \cdot K_{\mathrm{MBY}} \cdot K_{\mathrm{H}_{2}} \cdot C_{\mathrm{MBY}} \cdot C_{\mathrm{H}_{2}}}{\left(1+K_{\mathrm{MBY}} \cdot C_{\mathrm{MBY}}+\sqrt{K_{\mathrm{H}_{2}} \cdot C_{\mathrm{H}_{2}}}+K_{\mathrm{MBE}} \cdot C_{\mathrm{MBE}}+K_{\mathrm{MBA}} \cdot C_{\mathrm{MBA}}+K_{\mathrm{D}} \cdot C_{\mathrm{D}}\right)^{2}}$ & $(12)$ \\
\hline $\mathrm{MBE} \rightarrow \mathrm{MBA}$ & $r_{2}=\frac{k_{2} \cdot K_{\mathrm{MBE}}^{*} \cdot K_{\mathrm{MBE}} \cdot K_{\mathrm{H}_{2}} \cdot C_{\mathrm{MBE}} \cdot C_{\mathrm{H}_{2}}}{\left(1+K_{\mathrm{MBY}} \cdot C_{\mathrm{MBY}}+\sqrt{K_{\mathrm{H}_{2}} \cdot C_{\mathrm{H}_{2}}}+K_{\mathrm{MBE}} \cdot C_{\mathrm{MBE}}+K_{\mathrm{MBA}} \cdot C_{\mathrm{MBA}}+K_{\mathrm{D}} \cdot C_{\mathrm{D}}\right)^{2}}$ & (13) \\
\hline $\mathrm{MBY} \rightarrow \mathrm{MBA}$ & $r_{3}=\frac{k_{3} \cdot K_{\mathrm{MBY}}^{* * *} \cdot K_{\mathrm{MBY}}^{* *} \cdot K_{\mathrm{MBY}}^{*} K_{\mathrm{MBY}} \cdot K_{\mathrm{H}_{2}}^{2} \cdot C_{\mathrm{MBY}} \cdot C_{\mathrm{H}_{2}}^{2}}{\left(1+K_{\mathrm{MBY}} \cdot C_{\mathrm{MBY}}+\sqrt{K_{\mathrm{H}_{2}} \cdot C_{\mathrm{H}_{2}}}+K_{\mathrm{MBE}} \cdot C_{\mathrm{MBE}}+K_{\mathrm{MBA}} \cdot C_{\mathrm{MBA}}+K_{\mathrm{D}} \cdot C_{\mathrm{D}}\right)^{2}}$ & $(14)$ \\
\hline $\mathrm{MBY} \rightarrow \mathrm{D}$ & $r_{4}=\frac{k_{4} \cdot K_{\mathrm{MBY}}^{*} \cdot K_{\mathrm{MBY}} \cdot K_{\mathrm{H}_{2}} \cdot C_{\mathrm{MBY}} \cdot C_{\mathrm{H}_{2}}}{\left(1+K_{\mathrm{MBY}} \cdot C_{\mathrm{MBY}}+\sqrt{K_{\mathrm{H}_{2}} \cdot C_{\mathrm{H}_{2}}}+K_{\mathrm{MBE}} \cdot C_{\mathrm{MBE}}+K_{\mathrm{MBA}} \cdot C_{\mathrm{MBA}}+K_{\mathrm{D}} \cdot C_{\mathrm{D}}\right)^{2}}$ & (15) \\
\hline
\end{tabular}

Table 2

\begin{tabular}{|c|c|c|}
\hline \multirow{2}{*}{$\frac{\text { Reaction }}{\mathrm{MBY} \rightarrow \mathrm{MBE}}$} & \multicolumn{2}{|l|}{ Langmuir-Hinshelwood simplified expressions } \\
\hline & $r_{1}=\frac{k_{1}^{\prime} \cdot C_{\mathrm{MBY}}}{\left(1+K_{\mathrm{MBY}} \cdot C_{\mathrm{MBY}}+\sqrt{K_{\mathrm{H}_{2}} \cdot C_{\mathrm{H}_{2}}}+K_{\mathrm{MBE}} \cdot C_{\mathrm{MBE}}+K \cdot\left(C_{\mathrm{MBA}}+C_{\mathrm{D}}\right)\right)^{2}}$ & (16) \\
\hline $\mathrm{MBE} \rightarrow \mathrm{MBA}$ & $r_{2}=\frac{k_{2}^{\prime} \cdot C_{\mathrm{MBE}}}{\left(1+K_{\mathrm{MBY}} \cdot C_{\mathrm{MBY}}+\sqrt{K_{\mathrm{H}_{2}} \cdot C_{\mathrm{H}_{2}}}+K_{\mathrm{MBE}} \cdot C_{\mathrm{MBE}}+K \cdot\left(C_{\mathrm{MBA}}+C_{\mathrm{D}}\right)\right)^{2}}$ & (17) \\
\hline $\mathrm{MBY} \rightarrow \mathrm{MBA}$ & $r_{3}=\frac{k_{3}^{\prime} \cdot C_{\mathrm{MBY}}}{\left(1+K_{\mathrm{MBY}} \cdot C_{\mathrm{MBY}}+\sqrt{K_{\mathrm{H}_{2}} \cdot C_{\mathrm{H}_{2}}}+K_{\mathrm{MBE}} \cdot C_{\mathrm{MBE}}+K \cdot\left(C_{\mathrm{MBA}}+C_{\mathrm{D}}\right)\right)^{2}}$ & $(18)$ \\
\hline $\mathrm{MBY} \rightarrow \mathrm{D}$ & $r_{4}=\frac{k_{4}^{\prime} \cdot C_{\mathrm{MBY}}}{\left(1+K_{\mathrm{MBY}} \cdot C_{\mathrm{MBY}}+\sqrt{K_{\mathrm{H}_{2}} \cdot C_{\mathrm{H}_{2}}}+K_{\mathrm{MBE}} \cdot C_{\mathrm{MBE}}+K \cdot\left(C_{\mathrm{MBA}}+C_{\mathrm{D}}\right)\right)^{2}}$ & (19) \\
\hline
\end{tabular}

Reaction rate expressions based on a Langmuir-Hinshelwood mechanism for the modelling of the hydrogenation of MBY.

Table 3

Simplified reaction rate expressions for the modelling of the hydrogenation of MBY. 
Table 4

Estimated apparent kinetic constants and adsorption constants for the hydrogenation of MBY. Conditions: see Fig. 2.

\begin{tabular}{llr}
\hline Parameter & Units & \multicolumn{1}{c}{ Value } \\
\hline $\begin{array}{l}\text { Model parameters } \\
k_{1}^{\prime}\end{array}$ & $\mathrm{L} \mathrm{mol}_{\mathrm{Pd}}^{-1} \mathrm{~S}^{-1}$ & \\
$k_{2}^{\prime}$ & $\mathrm{L} \mathrm{mol}_{\mathrm{Pd}}^{-1} \mathrm{~S}^{-1}$ & 99627.28 \\
$k_{3}^{\prime}$ & $\mathrm{L} \mathrm{mol}_{\mathrm{Pd}}^{-1} \mathrm{~S}^{-1}$ & 1884.84 \\
$k_{4}^{\prime}$ & $\mathrm{L} \mathrm{mol}_{\mathrm{Pd}}^{-1} \mathrm{~S}^{-1}$ & 915.49 \\
$K_{\mathrm{MBY}}$ & $\mathrm{L} \mathrm{mol}^{-1}$ & 479.29 \\
$K_{\mathrm{MBE}}$ & $\mathrm{L} \mathrm{mol}^{-1}$ & 17.50 \\
$K_{\mathrm{H}} C_{\mathrm{H}_{2}}$ & - & 1.97 \\
$K$ & $\mathrm{~L} \mathrm{~mol}^{-1}$ & 0.04 \\
& & 9.13 \\
\hline
\end{tabular}

$\frac{\mathrm{d} C_{\mathrm{MBA}}}{\mathrm{d} t}=\frac{n_{\mathrm{Pd}}}{V_{\mathrm{L}}}\left(r_{2}+r_{3}\right)$

$\frac{\mathrm{d} C_{\mathrm{D}}}{\mathrm{d} t}=\frac{n_{\mathrm{Pd}}}{V_{\mathrm{L}}} r_{4}$

Eqs. (8)-(11) and (16)-(19) from Table 3 were then solved simultaneously using Rosenbrock's method [33] with $C_{\mathrm{MBY}}=10.2 \mathrm{~mol} \mathrm{~L}^{-1}$ and $C_{\mathrm{MBE}}=C_{\mathrm{MBA}}=C_{\mathrm{D}}=0 \mathrm{~mol} \mathrm{~L}^{-1}$ as initial conditions and used to model the variation of the concentration of the different species in a given run. The Madon-Boudart test was used to ensure the kinetic regime [34]. In the absence of mass transfer limitations, the activity of a structure-sensitive reaction is proportional to the number of active sites, provided that the dispersion of the metal is invariant, thus yielding a constant activity per mol of $\mathrm{Pd}$. Five reactions were carried out with different Pd loadings, ranging from 0.04 to $0.21 \mathrm{wt} . \%$. The rate of the reaction per mol of Pd was found to vary 5\%, which was regarded as enough evidence to prove the kinetic regime.

Fig. 2 presents the fit which showed a square of the Pearson product moment correlation coefficient of over $99 \%$ confirming that the model is consistent with the experimental data. The same model was used to fit the hydrogenation of pure MBE giving a correlation coefficient of over $99 \%$.

The obtained parameters are shown in Table 4. The high selectivity towards the alkene can be explained by a stronger adsorption of the alkyne compared to that of the alkene, namely that the reaction is thermodynamically selective [8]. Indeed, $K_{\mathrm{MBY}}$ was found to be an order of magnitude higher than $K_{\mathrm{MBE}}$. The ratio of the adsorption equilibrium constants of an alkyne to an alkene is usually 100 for Pd catalysts [3,8]. The different ratio can be attributed to the presence of the $\mathrm{PdZn}$ phase, which is known to change the adsorption strength of the unsaturated hydrocarbons $[7,27]$. As it can be seen from Fig. 2, the rate of over-hydrogenation of MBE to MBA decreases. This can be explained by an active site poisoning with by-products, whose adsorption constant is higher than that of MBE. This also differs from the usual behaviour of Pd based catalysts and it can be equally explained by the presence of the $\mathrm{PdZn}$ phase: $\mathrm{Pd} / \mathrm{ZnO}$ systems catalyze oxidative methanol reforming via adsorption of the aliphatic alcohol [35]. The adsorption equilibrium constant of hydrogen was sensibly smaller than the rest. Thus, the catalyst coverage with dissociated hydrogen was negligible for the developed catalyst, as is frequently the case for monometallic Pd [3].

The enthalpy of adsorption for each product was calculated with expressions reported elsewhere [36]. Runs 3, 14 and 15 of Table 5 were modelled with the proposed expressions and the enthalpies estimated by means of an Arrhenius plot. The values obtained ranged from $-20 \mathrm{~kJ} \mathrm{~mol}^{-1}$ to $-30 \mathrm{~kJ} \mathrm{~mol}^{-1}$, which is in line with the data available in the literature [36,37].

\subsubsection{Estimation of the kinetic parameters by DOE}

In order to estimate the apparent activation energy and the reaction order towards hydrogen for the main reaction, Eq. (12) (Table 2) was simplified for initial conditions. In this case, it can be shrunk into a simple power rate law expression:

$r_{1}^{0}=k_{1}^{\prime \prime} C_{\mathrm{H}_{2}}^{n}$

where

$k_{1}^{\prime \prime}=\frac{k_{1} \cdot K_{\mathrm{MBY}}^{*} \cdot K_{\mathrm{MBY}} \cdot K_{\mathrm{H}_{2}} \cdot C_{\mathrm{MBY}}}{1+K_{\mathrm{MBY}} \cdot C_{\mathrm{MBY}}}$

If the apparent kinetic constant is expressed in terms of Arrenhius' law and the resulting expression is then linearized, the model equation results:

$\ln r_{1}^{0}=\ln A+n \ln C_{\mathrm{H}_{2}}-\frac{E_{\mathrm{a}}}{R} \frac{1}{T}$

The apparent activation energy is known to include the influence of the heat of adsorption of the species involved in the reaction, thus a linear influence of the temperature cannot be taken for granted. As a result, Eq. (22) can be compared to a parametric model:

$z=a_{0}+a_{1} u_{1}+a_{2} u_{2}+a_{12} u_{1} u_{2}+a_{11} u_{1}^{2}+a_{22} u_{2}^{2}+\varepsilon$

where the variables $u_{1}$ and $u_{2}$ are $\ln C_{\mathrm{H}_{2}}$ and $1 / T$, respectively. The parameters that will be estimated, $a_{0}, a_{1}, a_{2}$ are $\ln A, n$ and $-E_{\mathrm{a}} / R$, respectively and $a_{12}, a_{11}$ and $a_{22}$ are constants that are related with interactions between the variables.

It is worth noting that in order to ease the calculations and generalize the methods in DOE, the variables are normalized so as to work with variables centred in zero and varying in the interval $[-1,1]$.

Table 5

Experimental layout and kinetic parameters of MBY hydrogenation to MBE

\begin{tabular}{|c|c|c|c|c|c|c|c|c|}
\hline \multirow[t]{2}{*}{ Design } & \multirow[t]{2}{*}{ Run } & \multicolumn{2}{|c|}{ Standardized variables } & \multicolumn{2}{|l|}{ Real variables } & \multirow{2}{*}{\multicolumn{2}{|c|}{ Reaction rate $\left(\mathrm{mol} \mathrm{mol}_{\mathrm{Pd}}^{-1} \mathrm{~s}^{-1}\right)$}} & \\
\hline & & $u_{1}$ & $u_{2}$ & $C_{\mathrm{H}_{2}}\left(\mathrm{~mol} / \mathrm{m}^{3}\right)$ & $T\left({ }^{\circ} \mathrm{C}\right)$ & & & \\
\hline \multirow[t]{4}{*}{ FFD } & 1 & -1 & -1 & 5.9 & 75 & & $10.12^{(13)}$ & \\
\hline & 2 & -1 & 1 & 5.9 & 35 & $3.78^{(1)}$ & $3.31^{(8)}$ & \\
\hline & 3 & 1 & -1 & 19.2 & 75 & $38.59^{(4)}$ & $33.66^{(5)}$ & $36.59^{(9)}$ \\
\hline & 4 & 1 & 1 & 19.2 & 35 & $11.49^{(2)}$ & $12.16^{(7)}$ & $12.88^{(11)}$ \\
\hline Center point & 5 & 0 & -0.06 & 10.6 & 55 & $12.71^{(3)}$ & $12.83^{(6)}$ & $12.64^{(10)}$ \\
\hline \multirow[t]{4}{*}{ Star design } & 6 & -1.15 & -0.06 & 5.4 & 55 & $5.59^{(12)}$ & $4.20^{(19)}$ & $5.68^{(23)}$ \\
\hline & 7 & 1.16 & -0.06 & 20.9 & 55 & $19.35^{(16)}$ & $17.18^{(18)}$ & $18.92^{(22)}$ \\
\hline & 8 & 0 & -1.13 & 10.6 & 78 & $18.32^{(14)}$ & $18.96^{(17)}$ & \\
\hline & 9 & 0 & 1.17 & 10.6 & 32 & $5.13^{(15)}$ & $4.31^{(20)}$ & $4.90^{(21)}$ \\
\hline
\end{tabular}

\footnotetext{
${ }^{(n)}$ The superscripts give the order in which the runs were performed.
} 


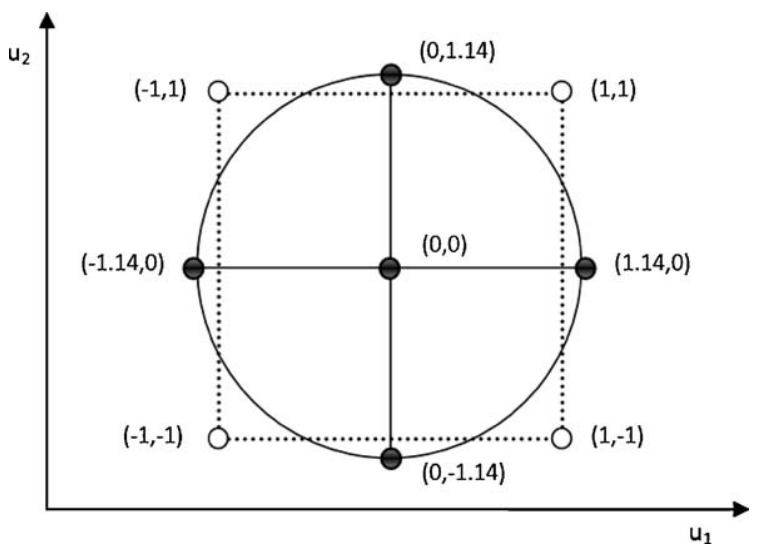

Fig. 5. Layout of the experiments in a 2-factor central composite design. ( $\bigcirc)$ Full factorial design; ( $(\bullet)$ star design (see Section 3.5 and Table 5 for detailed information).

To rule out the possibility of quadratic and interaction effects, a central composite design (CCD) was performed (see Fig. 5). This design is the combination of a full factorial design (FFD) (white dots, Fig. 5) and a star design (black dots, Fig. 5). It can be seen that the experimental points situated in the star design are placed slightly out of the FFD square. This is done in order to keep the property of isovariance per rotation (or rotatability) and the orthogonality of the model [18]. Table 5 shows the corresponding reaction conditions for each point of Fig. 5 as well as the results obtained. The discrepancy between the position of the standardized variables in Fig. 5 and the experimental points shown in Table 5 is a result of the accuracy in the control of the temperature and hydrogen concentration.

In order to estimate the total run-to-run variability, and considering that many genuine replicas were available for each set of conditions, a pooled estimate of the standard deviation was calculated rather than the error only in the center point [18]. The total run-to-run variability was found to be 0.81 .

The system was solved with a least squares fit and the obtained parameters were analyzed by an analysis of the variance (ANOVA) test. In this test, the parameters are tested by means of the F-ratio, which compares the variance of a given parameter with that of the error of the model. A $P$-value of over $5 \%$ indicates that the given parameter can be considered as noise. Table 6 shows the initial ANOVA table where all parameters of Eq. (23) were considered. It can be seen that only the intercept and the first-order parameters $\left(a_{0}, a_{1}, a_{2}\right)$ are statistically relevant. The ANOVA test has to be repeated once the non-relevant parameters are eliminated (Table 7). In this case, it was proven that the remaining parameters were statistically relevant to the model. The apparent activation energy was found to be $25.2 \pm 1.6 \mathrm{~kJ} \mathrm{~mol}^{-1}$, which is in line with the values reported for the hydrogenation of 2-butyne-1,4-diol [38]. The

Table 6

Initial ANOVA table for the modeling of the MBY hydrogenation to MBE.

\begin{tabular}{lcllll}
\hline Source & DF & SS & MS & F & $P$ \\
\hline Model & 5 & 11.87 & 2.37 & 102.49 & $<0.0001$ \\
$a_{1}$ & 1 & 5.86 & 5.86 & 252.93 & $<0.0001$ \\
$a_{2}$ & 1 & 4.43 & 4.43 & 191.40 & $<0.0001$ \\
$a_{12}$ & 1 & 0.0001 & 0.0001 & 0.005 & 0.95 \\
$a_{11}$ & 1 & 0.006 & 0.006 & 0.26 & 0.61 \\
$a_{22}$ & 1 & 0.0004 & 0.0004 & 0.017 & 0.90 \\
Error & 17 & 0.39 & & & \\
Total & 22 & 12.26 & & & \\
\hline
\end{tabular}

Table 7

Final ANOVA table for the modeling of the MBY hydrogenation to MBE.

\begin{tabular}{lrrlll}
\hline Source & DF & \multicolumn{1}{l}{ SS } & MS & F & P \\
\hline Model & 2 & 11.86 & 5.93 & 296.63 & $<0.0001$ \\
$a_{1}$ & 1 & 6.01 & 6.01 & 300.35 & $<0.0001$ \\
$a_{2}$ & 1 & 4.96 & 4.96 & 247.91 & $<0.0001$ \\
Error & 20 & 0.40 & & & \\
Total & 22 & 12.26 & & & \\
\hline
\end{tabular}

Table 8

Apparent activation energy, $E_{\mathrm{a}}$, the reaction order on hydrogen, $n$, and preexponential factor, $A$, for the MBY semi-hydrogenation to MBE.

\begin{tabular}{lrlllllll}
\hline \multicolumn{2}{l}{ Model parameters } & & & \multicolumn{2}{l}{ Real parameters } \\
\cline { 1 - 1 } Parameter & Value & S.E. & & Parameter & Units & Value & S.E. \\
\hline$a_{0}$ & 2.37 & 0.030 & & $A$ & $\mathrm{~m}^{3} \mathrm{~mol}_{\mathrm{Pd}}^{-1} \mathrm{~s}^{-1}$ & 8963 & 2.01 \\
$a_{1}$ & 0.60 & 0.035 & & $n$ & - & 1.03 & 0.059 \\
$a_{2}$ & -0.57 & 0.036 & & $E_{\mathrm{a}}$ & $\mathrm{kJ} \mathrm{mol}^{-1}$ & 25.2 & 1.6 \\
\hline
\end{tabular}

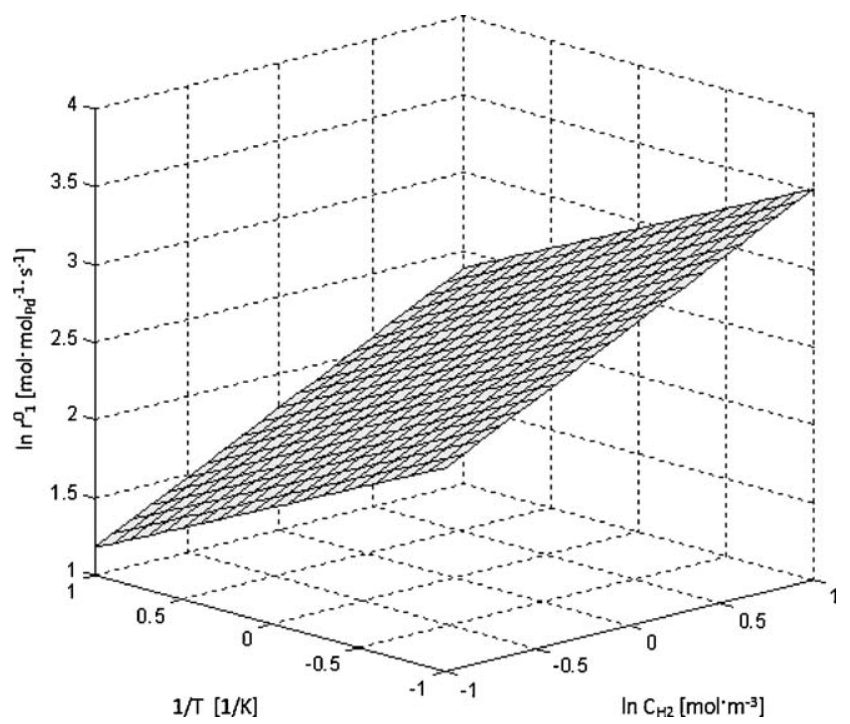

Fig. 6. Dependence of the initial rate of the MBY hydrogenation to MBE on temperature and $\mathrm{H}_{2}$ pressure as obtained by DOE.

reaction order towards hydrogen was found to be $1.03 \pm 0.06$ (see Table 8), as can be found in the literature for hydrogenation over Pt group metals $[3,16]$.

With the results obtained by DOE it was possible to establish a model that allows the estimation of the initial reaction rate for a given temperature and hydrogen concentration in a wide range of conditions:

$\ln r_{1}^{0}=9.2+\ln C_{\mathrm{H}_{2}}-3031 \frac{1}{T}$

where the concentration is expressed in $\left(\mathrm{mol} \mathrm{m}^{-3}\right)$ and the temperature in (K). Fig. 6 shows the graphical representation of this model which had a correlation coefficient of $97 \%$.

\section{Conclusions}

A structured $\mathrm{Pd} / \mathrm{ZnO} / \mathrm{SMF}$ catalyst was tested in the industrially relevant solvent-free hydrogenation of 2-methyl-3-butyn-2-ol 
(MBY). This catalyst had already shown an excellent performance in the water-assisted hydrogenation of MBY. The deliberate formation of an inter-metallic PdZn phase was avoided during the catalyst preparation. However, a PdZn phase was found to form spontaneously during the reuse of the catalyst. An-order-of-magnitude higher activity was observed as compared to the water-assisted hydrogenation. The catalyst deactivated by $38 \%$ during reuse while the selectivity towards MBE increased by $\sim 0.5 \%$. Part of the deactivation is due to the leaching of Pd from the catalyst surface. Nonetheless, the proliferation of the inter-metallic PdZn phase is regarded as the main cause for the further loss of activity and the increase of selectivity. The developed $\mathrm{Pd} / \mathrm{ZnO} / \mathrm{SMF}$ was $~ 50 \%$ more active than the industrial Lindlar catalyst. The reaction kinetics was modelled using a Langmuir-Hinshelwood mechanism. The kinetic parameters were estimated using a DOE approach showing the firstorder towards hydrogen pressure. The apparent activation energy was found to be $25.2 \pm 1.6 \mathrm{~kJ} \mathrm{~mol}^{-1}$. The catalyst is currently being tested in a continuous solvent-free MBY hydrogenation carried out in a SBCR and the results will be reported elsewhere.

\section{Acknowledgements}

The authors thank Nicolas Xanthopoulos (EPFL-STI-IMX-LMCH) for performing the XPS measurements. The financial support from the Swiss National Science Foundation and the EU "IDECAT" network of excellence is highly appreciated.

\section{References}

[1] B. Chen, et al., New developments in hydrogenation catalysis particularly in synthesis of fine and intermediate chemicals, Appl. Catal. A 280 (2005) 17-46.

[2] F. Roessler, Catalytic hydrogenation in the liquid phase, Chimia 57 (12) (2003) 791-798.

[3] E. Joannet, et al., Palladium supported on filamentous active carbon as effective catalyst for liquid-phase hydrogenation of 2-butyne-1,4-diol to 2-butene-1,4diol, Chem. Eng. Sci. 57 (16) (2002) 3453-3460

[4] N.A. Zakarina, et al., Monodispersed palladium catalysts in the hydrogenation of dimethylethynylcarbinol, Kinet. Catal. 24 (4) (1983) 733-737.

[5] G.D. Zakumbaeva, et al., Properties of monodisperse Pd/MgO catalysts, Kinet. Catal. 24 (2) (1983) 379-383.

[6] P. Kacer, L. Cerveny, Structure effects in hydrogenation reactions on noble metal catalysts, Appl. Catal. A 229 (2002) 193-216.

[7] D.V. Sokol'skii, et al., Catalytic properties of the Pd-ZnO system in hydrogenation reactions, Russ. J. Phys. Chem. 60 (11) (1986) 1639-1641.

[8] A. Molnar, A. Sarkany, M. Varga, Hydrogenation of carbon-carbon multiple bonds: chemo-, regio- and stereo-selectivity, J. Mol. Catal. A 173 (2001) 185-221.

[9] R. Tschan, et al., Continuous semihydrogenation of a propargylic alcohol over amorphous $\mathrm{Pd}_{81} \mathrm{Si}_{19}$ in dense carbon dioxide: effect of modifiers, Catal. Lett. 75 (2001) 31-36.

[10] H. Lindlar, Ein Neuer Katalysator Fur Selektive Hydrierungen, Helv. Chim. Acta 35 (2) (1952) 446-456.

[11] A. Bruehwiler, et al., Three-phase catalytic hydrogenation of a functionalized alkyne: mass transfer and kinetic studies with in situ hydrogen monitoring, Ind. Eng. Chem. Res. 47 (18) (2008) 6862-6869.
[12] L. Kiwi-Minsker, E. Joannet, A. Renken, Loop reactor staged with structured fibrous catalytic layers for liquid-phase hydrogenations, Chem. Eng. Sci. 59 (22-23) (2004) 4919-4925.

[13] M. Grasemann, et al., Hydrodynamics of a bubble column reactor staged with sintered metal fiber catalyst for continuous three-phase hydrogenation, Ind. Eng. Chem. Res. (2007)

[14] V. Holler, et al., Bubble columns staged with structured fibrous catalytic layers: residence time distribution and mass transfer, Ind. Eng. Chem. Res. 40 (6) (2001) 1575-1579.

[15] N. Semagina, et al., Structured catalyst of Pd/ZnO on sintered metal fibers for 2methyl-3-butyn-2-ol selective hydrogenation, J. Catal. 251 (1) (2007) 213222 .

[16] U.K. Singh, M. Albert Vannice, Liquid-phase hydrogenation of citral over Pt/SiO catalysts. I. Temperature effects on activity and selectivity, J. Catal. 191 (1) (2000) 165-180.

[17] V. Czitrom, One-factor-at-a-time versus designed experiments, Am. Stat. 53 (2) (1999) 126-131.

[18] G.E.P. Box, J.S. Hunter, W.G. Hunter, Statistics for Experimenters. Design Innovation and Discovery, Wiley-Interscience, 2005.

[19] M.M. Barsan, F.C. Thyrion, Kinetic study of oxidative dehydrogenation of propane over Ni-Co molybdate catalyst, Catal. Today 81 (2) (2003) 159-170.

[20] H.M. da Costa, et al., Design and analysis of experiments in silica filled natural rubber compounds-effect of castor oil, Polym. Test. 22 (7) (2003) 769-777.

[21] D.M. Roberge, An integrated approach combining reaction engineering and design of experiments for optimizing reactions, Org. Process Res. Dev. 8 (6)(2004) 10491053.

[22] I. Yuranov, L. Kiwi-Minsker, A. Renken, Structured combustion catalysts based on sintered metal fibre filters, Appl. Catal. B 43 (2003) 217-227.

[23] M. Meyberg, F. Roessler, In situ measurement of steady-state hydrogen concentrations during a hydrogenation reaction in a gas-inducing stirred slurry reactor, Ind. Eng. Chem. Res. 44 (25) (2005) 9705-9711.

[24] A. Sarkany, et al., Hydrogenation of 1-butene and 1, 3-butadiene mixtures over Pd/ZnO catalysts, J. Catal. 141 (1993) 566-582.

[25] M.A. Aramendia, et al., Optimization of the selective semi-hydrogenation of phenylacetylene with supported palladium systems, Appl. Catal. 63 (1) (1990) 375-389.

[26] N. Iwasa, et al., Steam reforming of methanol over Pd/ZnO: effect of formation of PdZn alloys upon the reaction, Appl. Catal. A 125 (1995) 145-157.

[27] G.D. Zakumbaeva, et al., Effect of the metal-carrier interaction on the properties of Pd/ZnO catalysts, Russ. J. Phys. Chem. 61 (6) (1987) 801-804.

[28] M. Besson, P. Gallezot, Deactivation of metal catalysts in liquid phase organic reactions, Catal. Today 81 (4) (2003) 547-559.

[29] S. Asplund, et al., Catalyst deactivation in liquid-phase and gas-phase hydrogenation of acetylene using a monolithic catalyst reactor, Catal. Today 24 (1-2) (1995) 181-187.

[30] B. Coq, F. Figueras, Bimetallic palladium catalysts: influence of the co-metal on the catalyst performance, J. Mol. Catal. A 173 (2001) 117-134.

[31] G.D. Zakumbaeva, et al., Selective hydrogenation of dimethylethynylcarbinol under production conditions, Russ. J. Appl. Chem. 54 (5) (1981) 980-982.

[32] U.K. Singh, M.A. Vannice, Liquid-phase hydrogenation of citral over Pt/SiO catalysts, J. Catal. 191 (2000) 165-180.

[33] H.H. Rosenbrock, C. Storey, Computational Techniques for Chemical Engineers, Pergamon Press, Oxford, 1966.

[34] R.J. Madon, M. Boudart, Experimental criterion for the absence of artifacts in the measurement of rates of heterogeneous catalytic reactions, Ind. Eng. Chem. Fundam. 21 (4) (1982) 438-447.

[35] S. Liu, et al., Hydrogen production by oxidative methanol reforming on $\mathrm{Pd} / \mathrm{ZnO}$ : catalyst deactivation, Appl. Catal. A 299 (2006) 58-65.

[36] U.K. Singh, M.A. Vannice, Kinetic and thermodynamic analysis of liquid-phase benzene hydrogenation, AIChE J. 45 (5) (1999) 1059-1071.

[38] N. Semagina, et al., Palladium nanoparticles stabilized in block-copolymer micelles for highly selective 2-butyne-1,4-diol partial hydrogenation, Appl. Catal. A-Gen. 280 (2) (2005) 141-147. 